Cómo citar este trabajo: Almeida-García, F., Cortés Macías, R., Gallegos Reina, A., \& Schenkel, E. (2018). Evolución hotelera y pautas de localización en Torremolinos. Boletín de la Asociación de Geógrafos Españoles, 79, 2535, 1-29. http://dx.doi.org/10.21138/bage.2535a

\title{
Patrones de localización y evolución hotelera: el caso de Torremolinos
}

Patterns of location and hotel evolution: the case of Torremolinos

\author{
Fernando Almeida-García \\ falmeida@uma.es \\ Facultad de Turismo \\ Universidad de Málaga (España)

\section{Rafael Cortés Macías} \\ rcortes@uma.es \\ Facultad de Turismo \\ Universidad de Málaga (España)
}

\author{
Antonio Gallegos Reina \\ a.gallegos@uma.es \\ Departamento de Geografía \\ Universidad de Málaga (España)
}

\author{
Erica Schenkel \\ erica.schenkel@uns.edu.ar \\ Departamento de Geografía y Turismo \\ Universidad Nacional del Sur (Argentina)
}

\section{Resumen}

Torremolinos constituye un caso destacable que resalta la estrecha vinculación que existe entre el tipo de desarrollo turístico y los patrones de localización de la industria hotelera. Este estudio muestra la evolución de un destino maduro de sol y playa, que ha creado una notable oferta 
hotelera a lo largo del tiempo. Para comprender la distribución temporal y espacial de la oferta hotelera, se propone un modelo de localización de la actividad hotelera. Las herramientas de análisis utilizadas han sido la recopilación de la información documental y estadística relativa a los hoteles, las ortofotografías aéreas para el estudio de los cambios de usos del suelo, el análisis estadístico para conocer el comportamiento espacial y el trabajo de campo para localizar los establecimientos hoteleros. La investigación comprueba la existencia de clusters espaciales como estrategia de implantación del sector hotelero de Torremolinos.

Palabras clave: localización hotelera; evolución del destino; destinos de sol y playa; Torremolinos; clusters.

\begin{abstract}
Torremolinos is a remarkable case that highlights the close link that exists between the type of tourism development and the localization patterns of the hotel industry. This study shows the evolution of a mature destination of sun and beach, which has created a notable hotel offer along the time. To understand the temporal and spatial distribution of the hotel offer, a model of location of the hotel activity is proposed. The analysis tools used have been the collection of documentary and statistical information on hotels, the aerial orthophotography for the study of changes in land use, statistical analysis to know spatial behavior and field work to locate the hotel establishments. The research proves the existence of spatial clusters as a strategy to place the hotel sector in Torremolinos.
\end{abstract}

Key words: hotel location; evolution of destination; seaside destinations; Torremolinos; clusters.

\title{
1 Introducción
}

Torremolinos se mantuvo durante mucho tiempo como un pequeño pueblo de agricultores y pescadores de la costa mediterránea española. Esta situación fue alterada primero por un turismo de élite en la década de 1930 y posteriormente por la llegada del turismo de masivo en 1960. Desde entonces el municipio no ha dejado de crecer hasta convertirse en uno de los referentes del turismo popular de sol y playa en España. Los primeros pequeños hoteles familiares, surgidos junto a la carretera nacional en el centro de la ciudad para un reducido turismo de elite, pronto dieron paso a una densa estructura hotelera, consolidada sobre la línea de costa, destinada al turismo de masas. El pequeño enclave mediterráneo ha pasado a ser un destino internacional.

Su evolución como destino constituye un caso destacable que permite conocer la vinculación directa que existe entre el desarrollo turístico y los patrones de localización impulsados por la industria hotelera. Los hoteles como "productos" primarios del turismo, y particularmente su ubicación, aportan una información fundamental para entender la evolución de la actividad en el territorio, a lo largo de diferentes etapas de desarrollo (Pereira, Claver y Molina, 2011; Yang, Wong \& Wang, 
2012; Lado-Sestayo et al., 2016). A pesar de que existan diversos estudios que abordan la localización de los hoteles, aún no se han realizado estudios de este tipo en la Costa del Sol, uno de los principales destinos turísticos a escala mundial. La mayoría de estos estudios se han centrado en áreas urbanas, desconociendo la particular ocupación del territorio que hace esta industria turística en los destinos de sol y playa (Yang, Luo \& Law, 2014).

El municipio de Torremolinos en 2016 tenía una población de 67.2786 habitantes, una extensión de $19,8 \mathrm{~km}^{2}$ y una densidad demográfica de $34235,7 \mathrm{hab} . / \mathrm{km}^{2}$. Se localiza en la provincia de Málaga, dentro de la Costa del Sol, entre los municipios de Málaga y Benalmádena (Figura 1). Torremolinos se segregó del municipio de Málaga en 1988. El territorio que ocupa el espacio urbano es una estrecha franja de tierra entre la Sierra de Mijas y el Mar Mediterráneo. El municipio se puede dividir en tres áreas principales: (i) la zona de montaña que es parte de la Sierra de Mijas, un cordón montañoso que se presenta como telón de fondo de la zona más oriental de la Costa del Sol; (ii) el piedemonte, donde se asentaba la villa agrícola y en la actualidad el casco tradicional y (iii) la zona litoral, separada de la anterior área mediante un acantilado, ocupada por antiguos asentamientos pesqueros (Carihuela y Bajondillo), zonas de pasto extensivo y cultivos como el de caña de azúcar (García y Ocaña, 1982). Esta distribución hizo que la zona litoral tuviera una difícil comunicación, ya que la antigua carretera Nacional 340 pasaba por el piedemonte. Así mismo, en el litoral predominaba la gran propiedad, lo que favoreció la creación de grandes complejos hoteleros.

\section{Figura 1. Localización del municipio de Torremolinos}
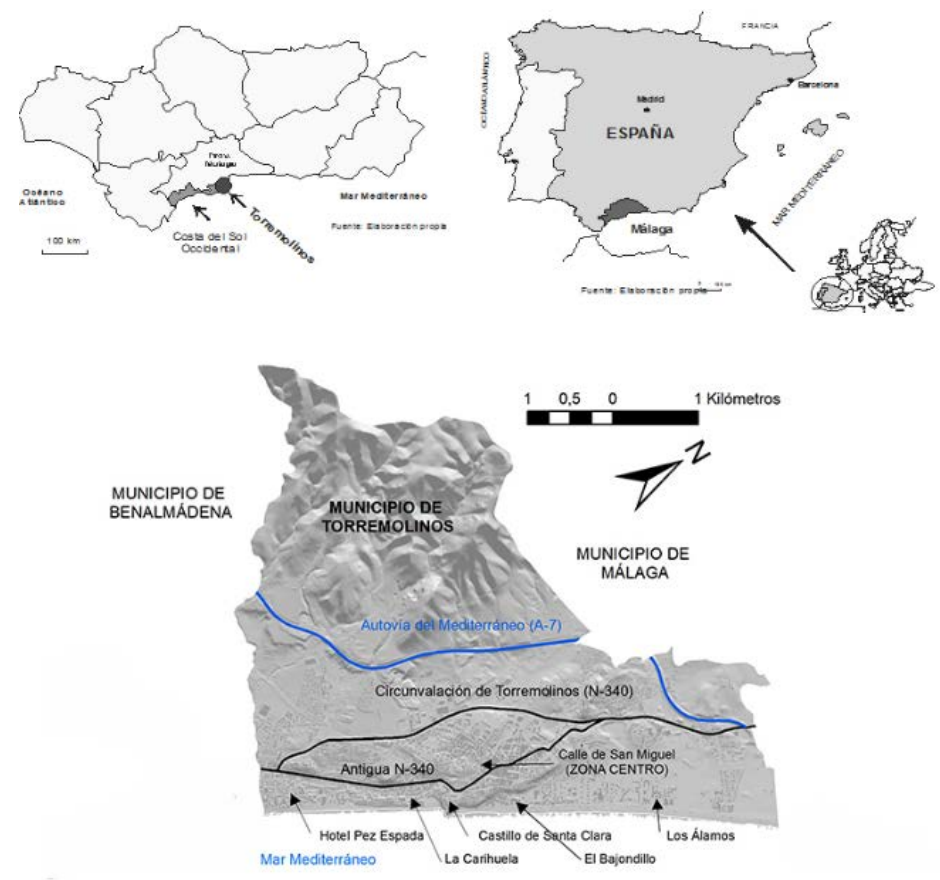

Fuente: elaboración propia 
Torremolinos ha experimentado un gran crecimiento de la oferta de alojamiento turística y en especial hotelera en los últimos 50 años. En 2016 Torremolinos presentaba el mayor número de plazas de alojamiento reglado de la Costa del Sol (con un 24,3\% del total), concentrando el 18,7\% de la oferta de la provincia de Málaga y el 7,2\% de Andalucía (IECA, 2017). El volumen total de plazas turísticas se estimó en 82341 de las cuales 27990 son de establecimientos reglados (34\%) y 54351 de oferta no reglada-vivienda turística (66,3\%), lo que supone una densidad de la oferta turística de 4137 plazas $/ \mathrm{km}^{2}$ (IECA, 2017). Torremolinos permanecía en 2017 entre los quince primeros destinos españoles en cuanto a mayor número de pernoctaciones y plazas hoteleras (INE, 2017).

La investigación pretende contribuir al análisis de la localización de la oferta hotelera en la Costa del Sol, a partir del análisis de Torremolinos como caso de estudio. Este trabajo busca identificar los factores que intervienen en la ubicación de los hoteles en el territorio, describir sus cambios en los diferentes periodos históricos y conocer los comportamientos territoriales de los establecimientos hoteleros en relación a su actividad económica.

\section{La localización de los hoteles como objeto de estudio}

El estudio de variables de localización de actividades económicas ha sido materia de diversos análisis, sustentados en métodos, tanto explicativos como predictivos y tanto teóricos como empíricos (Averbakh \& Berman, 1995; Yang \& An, 1997; Porter, 2000; Cheng \& Li, 2004). Estos modelos ponen de relieve los conflictos existentes entre las empresas a la hora de ubicarse y requerir similares recursos (Hannan \& Freeman, 1989). Los modelos ecológicos de localización destacan que las organizaciones similares compiten más intensamente por los recursos, y que en dicha competición el tamaño de la organización tiene una importancia singular (Hannan \& Freeman, 1989). Las grandes empresas tienden a ocupar los espacios centrales, obligando al resto de organizaciones a desarrollar estrategias de supervivencia: especialización, diferenciación, etc. (Baum \& Singh, 1994). Por otro lado, los modelos de la economía espacial muestran que las empresas especializadas en similares actividades, tienden más a la agrupación que a la dispersión (Greenhut, Norman \& Hung, 1987), hecho que como se verá tiene una singular importancia en el destino estudiado.

Los estudios de la localización de los establecimientos hoteleros han ido aumentando en las últimas décadas, tanto a escala internacional, nacional como intra-metropolitana (Yang, Luo \& Law, 2014). La localización geográfica de los hoteles tiene una especial importancia debido a que su viabilidad económica está estrechamente relacionada con su ubicación y que estos establecimientos tienen una difícil relocalización posterior. Ante un mercado cada vez más competitivo, el análisis y la selección de la ubicación se ha convertido en una cuestión fundamental para el sector, para mantener la tasa de retorno de la inversión y aumentar la rentabilidad (Arbel \& Pizam, 1977; 
Urtasun \& Gutiérrez, 2006; Chou, Hsu \& Chen, 2008; Pereira, Claver \& Molina, 2011; Yang, Wong \& Wang, 2012; Lado-Sestayo et al., 2016). Como afirman Pereira, Claver y Molina (2011, p. 135):

la ventaja competitiva de una empresa no sólo depende de los recursos que controla sino también de los recursos a los que tiene acceso en su entorno inmediato

La decisión del emplazamiento se cristaliza en el tiempo, constituyendo un factor fundamental del rendimiento comercial, con impactos a largo plazo. Una eventual relocalización no implicará sólo una decisión difícil de ubicación, sino también un proceso general sumamente costoso (Yang, Lou \& Law, 2014; Lado-Sestayo et al., 2016).

Sin embargo, el interés por este tipo de estudios no se puede reducir únicamente a la dimensión de la gestión empresarial. El emplazamiento de los hoteles es parte del desarrollo urbano de cada destino asociado a elementos singulares como las vías de comunicación o los grandes equipamientos, además de la evolución del propio tejido urbano que se ha ido generando conjuntamente con los hoteles. Para Yang, Lou y Law (2014) los hoteles constituyen un elemento principal de la política urbana de un destino.

En este tipo de estudios, la perspectiva geográfica puede aportar una visión significativa, ya que identifica aquellas variables que condicionan el emplazamiento hotelero en el territorio, su integración o competencia con otras infraestructuras de la ciudad, así como sus impactos y patrones de distribución (Egan \& Nield, 2000; Shoval, 2006). La identificación de las variables que explican y, en cierta manera, predicen la localización de los hoteles es una cuestión compleja. En principio se puede afirmar que dichas variables se refieren tanto a las características del hotel, asociadas al tamaño, la cantidad y calidad de los servicios; como a los atributos de localización, que definen el destino, como puede ser la accesibilidad, la intervención gubernamental y las características de la playa (Baum \& Haveman, 1997; Rigall et al., 2011; Yang, Wong \& Wang, 2012; Urtasun \& Gutiérrez, 2006; Lado-Sestayo et al., 2016).

Entre las características individuales del establecimiento hotelero que pueden afectar a la localización, se pueden señalar:

a) La calificación de estrellas, que alude a los diferentes nichos de mercado en los que se posicionan los establecimientos. La localización suele estar condicionada por las preferencias de sus clientes, dando lugar a conjuntos de hoteles de categorías similares.

b) La diversidad de servicios también influye en la localización. Aquellos establecimientos que sólo ofrecen alojamiento suelen ubicarse en el centro del destino, donde el turista cuenta con los servicios requeridos próximos, mientras que los hoteles de todo incluido suelen ubicarse alejados del mismo. 
c) Y el tamaño. Esta variable está directamente relacionada con el aumento de la rentabilidad de un hotel debido a la economía de escala, de forma que se reducen, hasta cierto punto, los costes de mantenimiento a medida que se incrementa la oferta de plazas y servicios. Estos hoteles suelen necesitar una parcela extensa por lo que tienen que localizarse en zonas con amplia oferta de suelo (Yang, Wong \& Wang, 2012).

Estas características del establecimiento, se encontrarán condicionadas por los atributos del entorno en el cual se emplazan. Las variables que se incluyen en este grupo son:

a) La accesibilidad, que se refiere a la cercanía del hotel a los medios de transportes utilizados por los turistas y la proximidad a recursos y servicios turísticos singulares. La accesibilidad explica la ubicación de estos establecimientos en zonas céntricas, con diferentes servicios próximos a su disposición, la cercanía a otras instalaciones, como aeropuertos, estaciones de tren, o lugares de interés turístico. En este último caso, el emplazamiento cercano a la costa, constituye un elemento fundamental para los destinos de sol y playa. La investigación de Pereira, Claver y Molina (2011) en las Comunidades Autónomas, pone de manifiesto la influencia de la proximidad a la costa en el nivel de ocupación y en la ubicación cerca de la misma de los hoteles de mayor tamaño. Este atributo de accesibilidad se vincula directamente con el coste del suelo: la localización de un hotel en zonas con buena accesibilidad, se relaciona con hoteles con alta capacidad económica y un elevado precio por plaza (Chou, Hsu \& Chen, 2008). Esta relación es demostrada por diferentes investigaciones realizadas en el Mediterráneo (Papatheodorou, 2002; Rigall et al., 2011).

b) El acceso a determinados bienes y servicios públicos también promueve o limitan la localización hotelera, en función de disponer de una determinada calidad ambiental, seguridad pública, diversidad cultural o infraestructura, equipamiento e instalaciones básicas, influyendo tanto en los turistas como en los agentes oferentes de turismo (Yang, Wong \& Wang, 2012).

c) La intervención del gobierno en la distribución hotelera, con el impulso de medidas tales como la regulación del uso del suelo, la promoción y limitación de áreas urbanas o el otorgamiento de permisos de exclusividad, también influyen directamente en la localización de hoteles. Como argumenta Yang, Lou y Law (2014, p. 215):

El proceso de decisión de localización de hotel no es sólo resultado de las fuerzas de mercado, además se encuentra influenciado por otros factores como las políticas de gobierno.

d) Otra variable relevante, son las características de la playa, escasamente analizadas por la bibliografía específica. Aspectos como una buena amplitud y longitud de la costa, su preservación y biodiversidad, el tipo de arena, la calidad del agua, el uso de bandera azul y los servicios disponibles, como instalaciones y accesos para personas con alguna discapacidad, 
seguridad y sombrillas para alquiler, aumentan el precio del hotel y favorece la localización de nuevos hoteles (Rigall et al., 2011).

Una vez descrito este primer análisis transversal, es importante señalar que la influencia de estas variables, referidas a las características del hotel y a las particularidades de la ciudad o destino en el cual se emplaza el hotel, no son inmutables ni en el tiempo ni el espacio (Pereira, Claver \& Molina, 2011; Yang, Wong \& Wang, 2012). Las mismas se encuentran condicionadas por el dinamismo propio de cada destino y suelen variar a lo largo del tiempo, por este motivo la localización hotelera debe ser analizada mediante la dimensión temporal (Pons, Rullán \& Murray, 2014). Por ejemplo, como analiza Shoval (2006), es muy común que en los destinos turísticos se sucedan diferentes periodos de localización en relación con la evolución de sus vías de comunicación y los avances en los medios de transporte. Por otro lado, se ha puesto de manifiesto que la evolución espacio-temporal de los destinos turísticos litorales también está ligada a los ciclos económicos y los cambios económicos globales (Gormsen, 1981).

Esa relación en el binomio tiempo-espacio, pone de manifiesto la importancia de complementar el análisis transversal de la ubicación de los hoteles, con un análisis longitudinal de las etapas, que dé cuenta de su evolución. Cada destino muestra su particular estructura condicionante de la localización hotelera. La mayor parte de las variables analizadas, se recogen en la propuesta de análisis de la localización de los hoteles en destinos de sol y playa (Figura 2).

Figura 2. Modelo de localización de hoteles en destinos de sol y playa

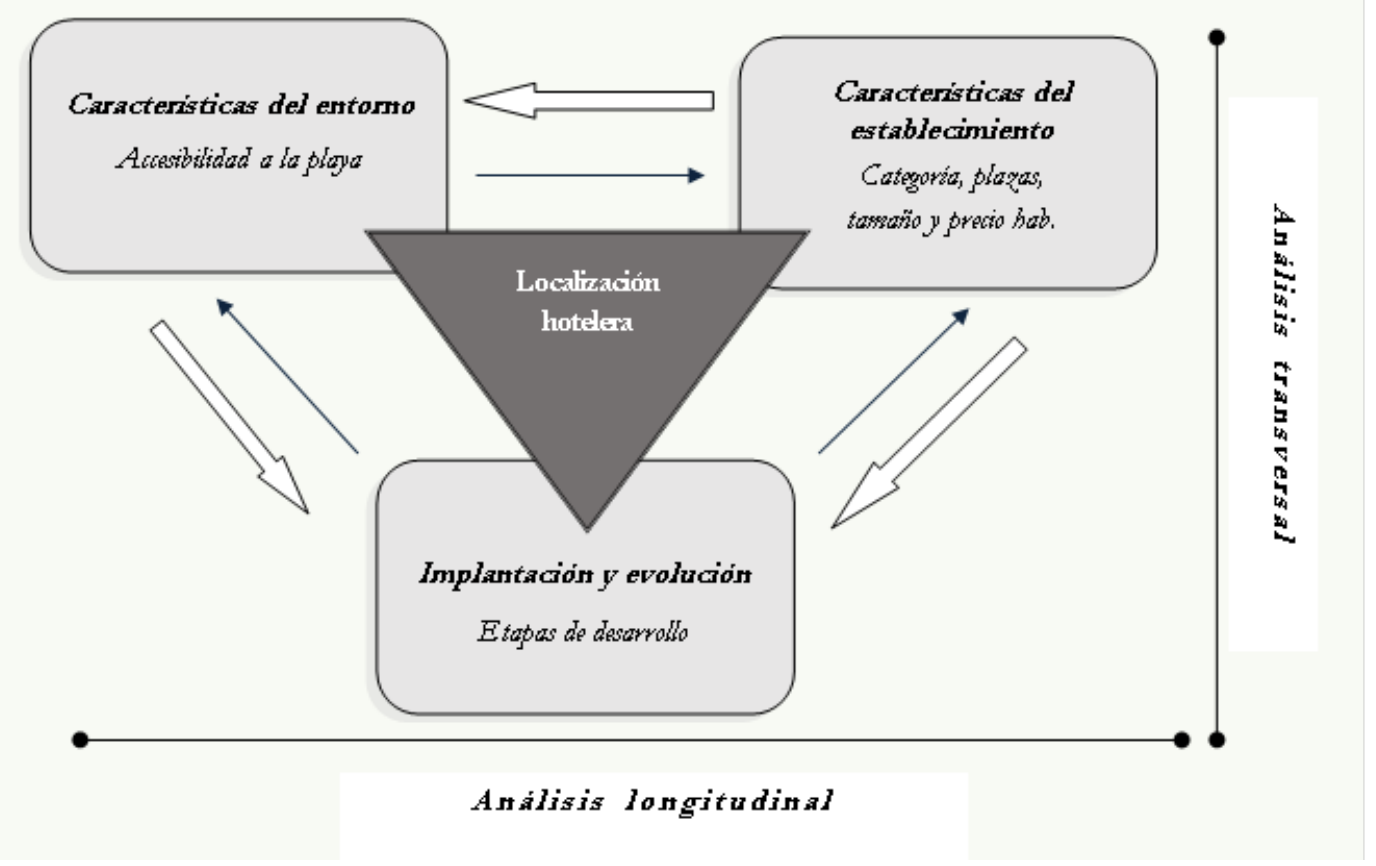

Fuente: elaboración propia 


\section{Metodología}

El modelo de análisis propuesto para la localización hotelera en destinos de sol y playa, combina un estudio transversal, circunscrito a las variables que caracterizan el entorno y aquellas otras que se refieren al propio establecimiento; con otro longitudinal, que incorpora la componente de implantación y evolución. A partir de estas categorías, se identificaron las siguientes variables para el caso de Torremolinos:

- Características del establecimiento hotelero': (1) número de estrellas (categoría del establecimiento), (2) plazas y (3) Tamaño (superficie de la parcela) y (4) precio de la habitación doble en temporada alta (euros).

- Características del entorno: (5) distancia a la playa (accesibilidad al principal recurso).

Los servicios y bienes públicos, medidas gubernamentales y características de la playa, no se incluyen en esta propuesta de análisis debido a que estimamos que son variables constantes para todos los establecimientos hoteleros analizados, y no producen una diferenciación en el modelo, aunque otros autores si las tienen en cuenta en otras escalas de estudio (Papatheodorou, 2002; Rigall et al., 2011; Pereira et al., 2011).

- Finalmente, se identifica la variable (6) antigüedad del hotel, que se incorpora en el análisis longitudinal (cronológico), siendo un atributo clave.

Esta propuesta introduce un mayor número de variables con respecto a anteriores modelos de localización hotelera como el de Baum y Haveman (1997) y Urtasun y Gutiérrez (2006). El primer modelo introdujo las variables de localización geográfica, precio y tamaño y el segundo, añadió la variable servicio. En ambos casos estos estudios están enfocados a hoteles urbanos. El presente modelo de análisis supone un avance para el estudio de la hotelería en los destinos de sol y playa.

Las fuentes utilizadas para conseguir la información relacionada con las variables de las características de los hoteles, han sido las Guías de Hoteles de Turespaña (Turespaña, 19952017), el Registro de Establecimientos Hoteleros de la Junta de Andalucía, las bases de datos del INE (Instituto Nacional de Estadística) e IECA (Instituto de Estadística y Cartografía de Andalucía), la base de datos de la Dirección General del Catastro (Ministerio de Hacienda y Función Pública, 2017) y páginas web de reservas hoteleras como Booking (2017) y Tripadvisor (2017). El precio de la habitación se obtuvo para el mes de agosto, coincidiendo con la temporada alta y procedente de las páginas web citadas. El precio se corresponde con una habitación doble. La parcela con la ubicación del hotel se ha obtenido de la base del catastro. Las guías hoteleras y bases de datos del

1 El estudio incluye como establecimientos hoteleros a los que se identifican como hoteles, hoteles-residencia y hotelesapartamento, según las fuentes consultadas. 
INE e IECA proporcionaron la información sobre las plazas, categoría y año de apertura del establecimiento.

El Sistema de Información Geográfica (SIG), (programa ArcGIS 9.3) ha permitido realizar una cartografía sobre la evolución del uso del suelo de Torremolinos y la localización hotelera. Para la elaboración de la cartografía digital destinada a analizar la evolución de los usos del suelo, se ha utilizado las ortofotografías aéreas y la base de usos del suelo disponible para los años 1957, 1977 y 2017. Así mismo, se analizaron las ortofotografías de otros años (1984, 1991 y 2007), aunque no han sido representados. La información alfanumérica asociada a las capas obtenidas, mantienen la estructura y contenido derivadas de la Guía Técnica de realización del Mapa de Usos y Coberturas Vegetales del Suelo en Andalucía 1:25 000, que a su vez procede del programa Corine Land Cover al mayor detalle disponible, tanto en las fuentes existentes como a través de la fotointerpretación (Ministerial Council, 2012).

Para obtener la capa de hoteles del SIG, se utilizó el Registro de Establecimientos Hoteleros de la Junta de Andalucía, la Guía de Hoteles de Turespaña (1995-2017) e información de bases de datos y cartografía catastral a fecha de febrero de 2017. La cartografía catastral se ha indexado con la base de datos catastral para el municipio de Torremolinos, permitiéndonos obtener un listado de establecimientos hoteleros, y aportando tanto información geográfica con los límites precisos de los recintos hoteleros como una amplia base de datos asociada con las variables objeto de análisis. Una vez incorporada la información espacial catastral de hoteles en el SIG, ha sido necesario un proceso de verificación individual de cada ítem. Esta revisión se ha realizado mediante el uso de herramientas como Google Maps, StreetView o Goolzoom, además de trabajo de campo, con visitas específicas a los establecimientos que presentaban dudas. Por último, el SIG ha permitido realizar el cálculo de la distancia de cada establecimiento hotelero respecto a la playa.

Mediante el programa Statgraphics XVII se realizó un análisis estadístico de conglomerados (clúster) para identificar las relaciones entre los hoteles inscritos en el Registro de Establecimientos Hoteleros a fecha de febrero de 2017. La realización de una agrupación jerárquica utilizando el método de Ward (distancia euclídea al cuadrado) permitió la identificación de los grupos de hoteles. En total se analizaron 59 hoteles que estaban abiertos en 2017. Las variables utilizadas para el análisis de clúster son las que se identifican en el modelo de análisis propuesto, que establece pautas de localización en el espacio y el tiempo (Figura 2 y Tabla 2). Los resultados del análisis estadístico se usaron para localizar en la cartografía los grupos de hoteles (Figura 11). Asimismo, se representaron junto con los datos obtenidos de la cartografía de los cambios de uso del suelo en el municipio. Los resultados de este análisis nos permitirán responder a la hipótesis que se plantea en esta investigación: 
Los establecimientos hoteleros tienen comportamientos territoriales diferenciados respecto a su localización dentro del destino de Torremolinos.

La investigación se centra en un estudio de caso, Torremolinos, que es representativo de un destino turístico consolidado. Acorde con la madurez del destino, en Torremolinos se observa en los últimos decenios una aminoración del desarrollo urbano y un freno en la apertura de nuevos establecimientos hoteleros, tras un período de fuerte crecimiento en el número de hoteles y en el tejido urbano entre las décadas de 1960 y 1990 (Priestley \& Mundet, 1998; Johnson, 2006).

\section{Análisis y resultados}

\subsection{Evolución de los cambios del uso del suelo y la actividad hotelera en Torremolinos}

Para entender la formación del destino turístico de Torremolinos y su relación con los hoteles, es preciso previamente conocer la evolución urbanística y territorial de la citada población. Por ello, se analiza la transformación que se ha producido entre los años 1957 y 2017, que representa la mayor parte del proceso de creación del destino. Antes de 1957 el impacto de la actividad turística fue muy escaso y se correspondía con el turismo de élite; posteriormente a esta fecha se inició el turismo de masas que produjo un gran consumo de suelo; a partir de 1977 se mantuvo la transformación del territorio aunque a un ritmo menor, frenándose este proceso a partir de 2008 debido a la crisis económica en España. Para este análisis se ha creado una cartografía de los usos del suelo a partir de la digitalización de la fotografía aérea de los años 1957, 1977 y 2017.

Con anterioridad a 1957, la actividad turística había llegado a Torremolinos, pero de forma muy puntual, mediante pequeños hoteles como el Santa Clara, creados entre fines de la década de los 20 y comienzo de los 30. En esta etapa fundacional predominaron los pequeños hoteles familiares, ubicados en el interior de la localidad, próximos a la carretera nacional y destinados a atender un reducido turismo de élite.

La imagen de 1957 muestra aún una población eminentemente agrícola y pesquera, como se podía encontrar en numerosas zonas del mediterráneo español en esas fechas. La superficie transformada apenas representa el $8 \%$ del municipio, siendo el uso predominante el forestal y natural, junto con el agrícola (Tabla 1). En Figura 3, en la categoría de tejido urbano, se observan dos núcleos urbanos consolidados, la zona central que se corresponde con la villa agrícola y otra área al oeste de Torremolinos (Montemar y Carihuela), que es un pequeño núcleo agrícola y pesquero. Así mismo, en la zona occidental se comprueba que se está produciendo una notable actividad transformadora y constructora. Entre estas construcciones destaca el hotel Pez Espada, el primer cinco estrellas de la Costa del Sol, que representa la irrupción de un nuevo modelo de desarrollo turístico: complejos turísticos aislados de la trama urbana consolidada, con una gran parcela. Son hoteles que disponen de amplias instalaciones y servicios. Se está reproduciendo la 
experiencia del Caribe y Florida en el Mediterráneo español para una demanda de alto poder adquisitivo.

Figura 3. Cambios de usos del suelo y localización hotelera en Torremolinos (1957)

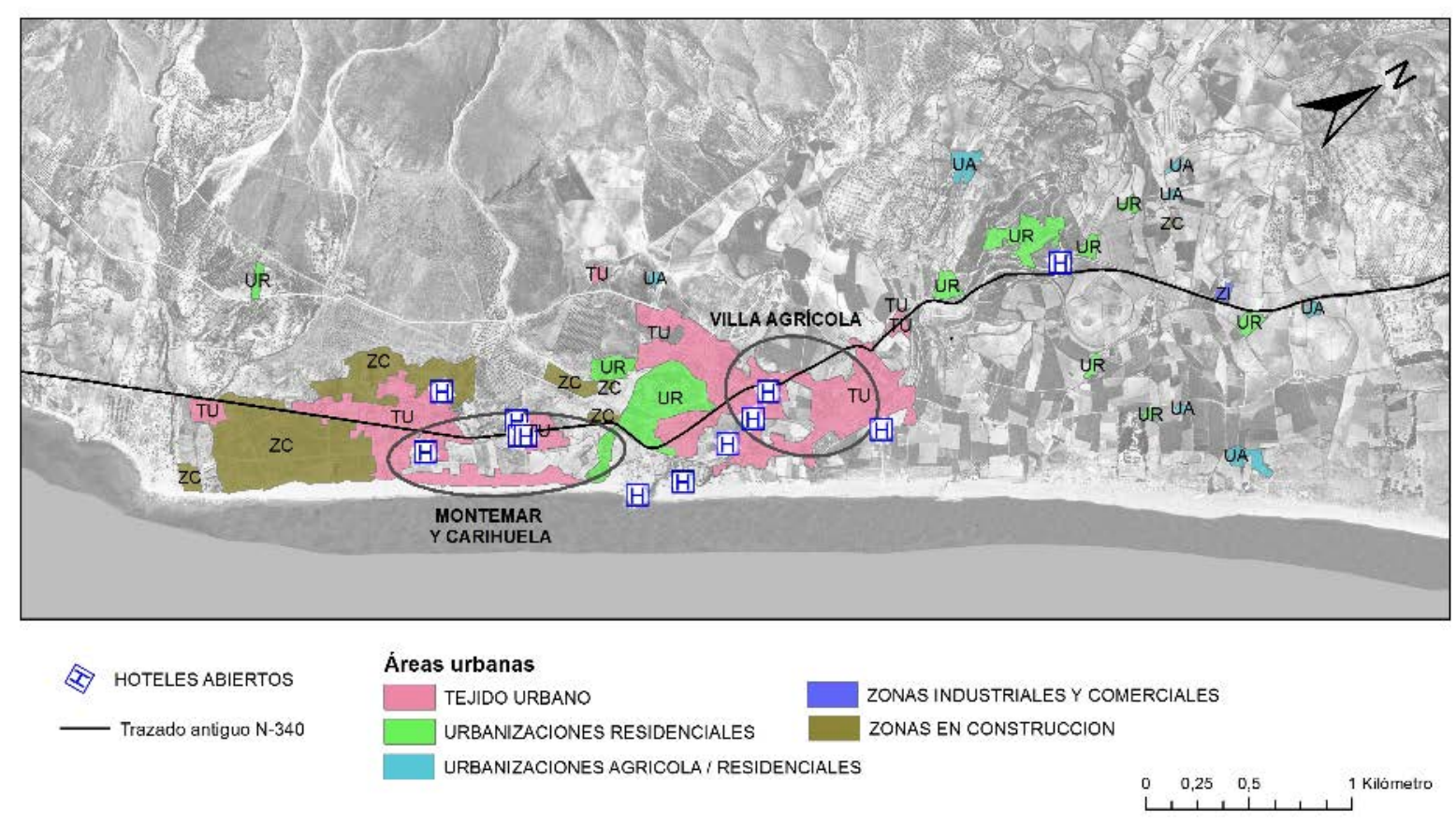

Fuente: elaboración propia

Entre los años 1958 y 1977 se originó un fuerte crecimiento de la oferta de alojamiento turístico (Figura 4). En esta etapa se produjo la explosión del turismo de masas, que no tuvo nada que ver con los pequeños hoteles de los años 30 y 40 . Al final de la década de los 70 la mayor parte de la zona turística de Torremolinos se había consolidado, alcanzado las 19000 plazas. En estos años la tasa de urbanización fue de 14,66 ha. por año, un hecho que se refleja en:

(a) El intenso crecimiento de la trama urbana (se ha triplicado el espacio urbano consolidado desde 75,9 hasta 242,4 hectáreas) (Tabla 1 y Figura 4).

(b) La expansión de los espacios residenciales (se quintuplica su superficie, de 24,8 a 134,5 ha.).

(c) El fuerte aumento de las zonas transformadas, vinculadas a las infraestructuras, instalaciones, etc.

Tras veinte años de crecimiento se generó un amplio tejido urbano continuo, a la vez que se expanden las urbanizaciones hacia las zonas periféricas del piedemonte de la sierra y hacia el extremo oriental del municipio. Prácticamente todo el frente litoral se había construido en esas fechas, a excepción de una pequeña parte en la zona más oriental (Los Álamos), que linda con el municipio de Málaga. 
Figura 4. Cambios de usos del suelo y localización hotelera en Torremolinos (1977)

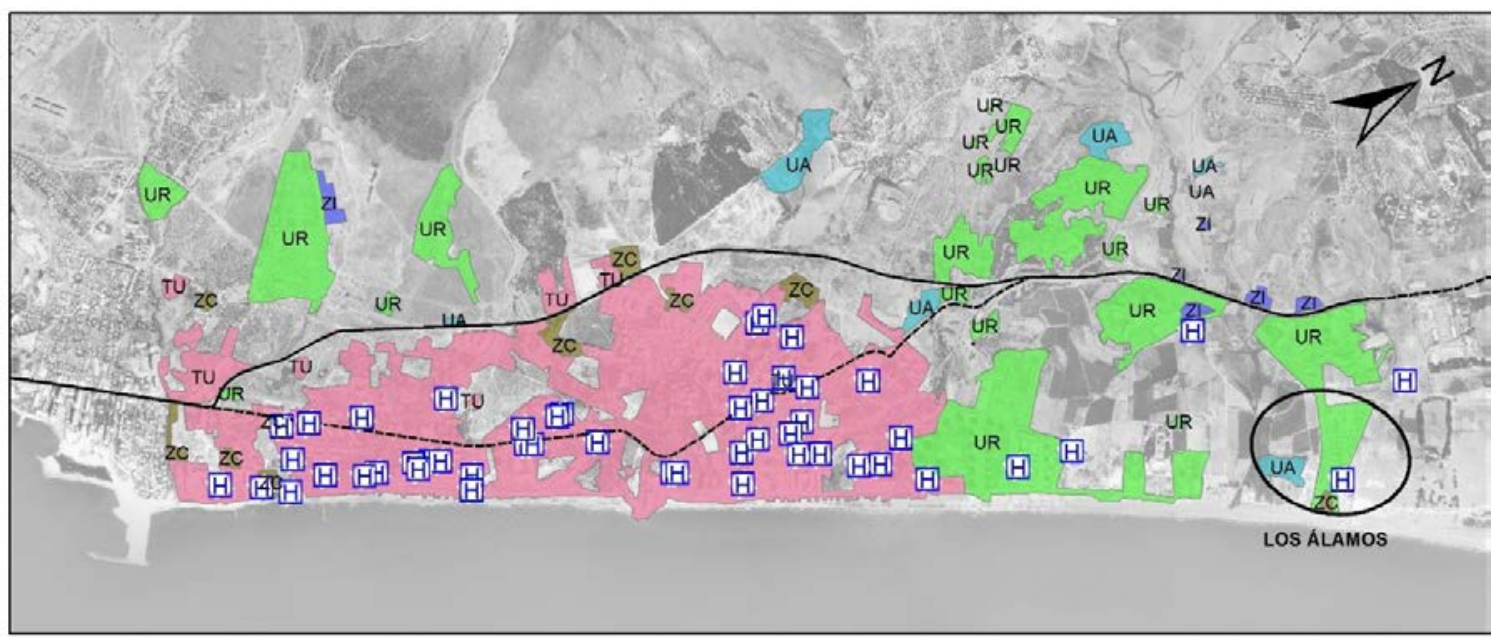

\& HOTELES ABIERTOS

\section{Áreas urbanas}

TEJIDO URBANO

- Trazado N-340

URBANIZACIONES RESIDENCIALES

ZONAS INDUSTRIALES Y COMERCIALES

URBANIZACIONES AGRICOLA/ RESIDENCIALES

ZONAS EN CONSTRUCCION

Fuente: elaboración propia

Tabla 1. Cambios de usos del suelo en Torremolinos (1957-2017)

\begin{tabular}{|c|c|c|c|c|c|c|}
\hline \multirow{2}{*}{ Usos del suelo } & \multicolumn{2}{|c|}{1957} & \multicolumn{2}{|c|}{1977} & \multicolumn{2}{|c|}{2017} \\
\hline & Has. & $\%$ & Has. & $\%$ & Has. & $\%$ \\
\hline Superficie construida y alterada & 157,3 & 8,0 & 435,9 & 22,1 & 908,6 & 45,8 \\
\hline Tejido urbano & 75,9 & & 242,4 & & 368,7 & \\
\hline Urbanizaciones residenciales & 24,8 & & 134,5 & & 264,5 & \\
\hline $\begin{array}{l}\text { Urbanizaciones agrícolas y } \\
\text { residenciales }\end{array}$ & 4,9 & & 13,0 & & 12,5 & \\
\hline Zonas industriales y comerciales & 0,5 & & 4,5 & & 50,4 & \\
\hline Zonas en construcción & 43,8 & & 10,2 & & 57,0 & \\
\hline Otras zonas transformadas & 7,4 & & 421,1 & & 155,6 & \\
\hline Superficie agrícola & 642,9 & 32,8 & 246,7 & 12,5 & 59,8 & 3,0 \\
\hline Superficie forestal y natural & 1160,3 & 59,2 & 1287,8 & 65,4 & $1.015,2$ & 51,2 \\
\hline Superficie total* & 1960,5 & 100,0 & 1970,4 & 100,0 & 1983,6 & 100,0 \\
\hline $\begin{array}{c}\text { Consumo suelo (sup. } \\
\text { Construido y alterado) } \\
\text { (ha./año) }\end{array}$ & & & $(195$ & & $\begin{array}{r}1 \\
(197\end{array}$ & \\
\hline
\end{tabular}

*Nota: variaciones en la superficie total relacionada con oscilaciones de la costa e instalaciones marítimas.

Fuente: elaboración propia 
El segundo periodo de análisis (1978 y 2017), se caracterizó por un notable crecimiento del superficie construida (472,7 ha.), de las cuales el tejido urbano supone 126,3 ha. Este cambio produjo un consumo de 12,1 ha./año durante esta fase. Este proceso se acompañó de una significativa expansión de la oferta hotelera que se dispersó por casi todo el destino. En 2017 se había ocupado y compactado prácticamente todo el frente costero, y el espacio agrícola quedó como algo testimonial (3\%), manteniéndose como zona no urbanizada principalmente la Sierra (51,3\%) (Tabla 1). La transformación urbanizadora sólo se ralentizó en dos breves periodos en la segunda fase, uno ligado a la crisis del petróleo y crisis económica posterior de España entre 1977 y 1984; y otra fase en los primeros años de la década de los 90 debido a la crisis del sector turístico. A partir de la década del 2000 se produce un fuerte crecimiento de la construcción ligada a la gran burbuja inmobiliaria española.

El análisis de la ortofotografía ratifica el incremento de la mancha urbana en 2017 (Figura 5). Sobre todo, se crece entre la primera circunvalación de Torremolinos y la Autovía del Mediterráneo y en torno a la zona próxima a la sierra, terminándose de compactar la franja costera. En 2017 se había urbanizado el $45,8 \%$ del municipio. Debido a las restricciones ambientales y urbano-territoriales, prácticamente se ha llegado al límite de lo urbanizable. Es muy llamativo el estancamiento casi absoluto del proceso urbanizador posterior a la burbuja inmobiliaria que estalló en 2008, entre 2007 y 2017 el ritmo urbanizador fue de 0,2 ha./año.

\section{Figura 5. Cambios de usos del suelo y localización hotelera en Torremolinos (2017)}
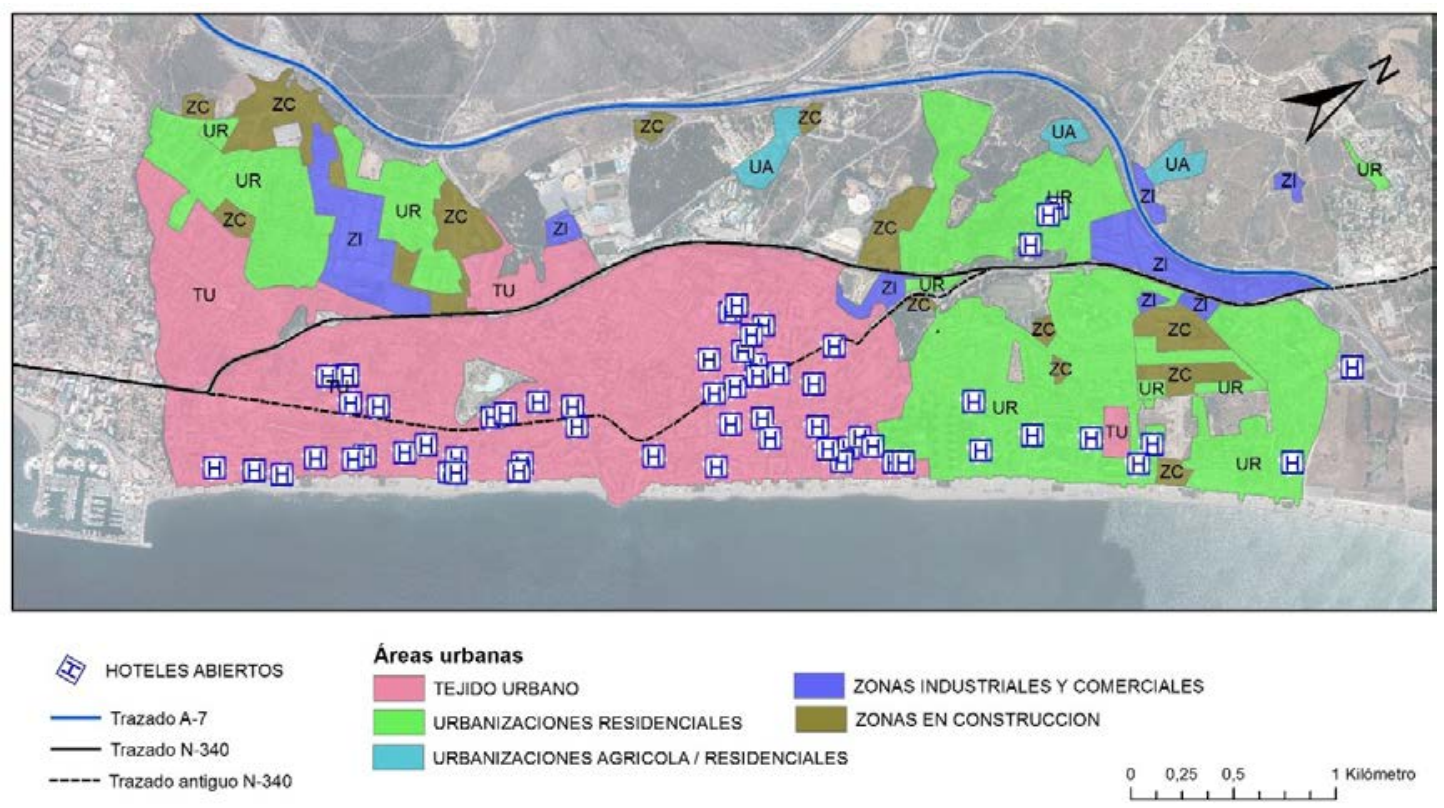

Fuente: elaboración propia

De forma concreta, el análisis territorial muestra una fuerte transformación del suelo del municipio entre 1957 y 2017. Entre esas fechas, la superficie construida o alterada se incrementó en 
751,3 ha. en detrimento del suelo agrícola $(-583,1$ ha.) y suelo forestal y natural $(-140,9$ ha.) (Figura 5 y Tabla 1).

\subsection{La implantación hotelera en Torremolinos: evolución de los patrones de localización}

El estudio de la localización hotelera está estrechamente relacionado con la evolución de Torremolinos como destino turístico. La importancia que la oferta hotelera ha jugado en la creación de este destino popular, ya fue destacada en los años 90 por Pollard y Domínguez (1993). Torremolinos tuvo un enorme crecimiento de su oferta de alojamiento durante el periodo del despegue del turismo de masas; se pasó de unas miles de camas en 1961 a casi 19000 en 1995, el máximo de la oferta hasta 2016. A partir de 1995 se produjo una disminución de la oferta debido a problemas estructurales del destino, a lo que se unió la crisis económica de 2008. Posteriormente ha habido una recuperación en 2016, acercándose la oferta al máximo histórico (Figura 6).

El análisis de la evolución de la oferta hotelera ha tenido en cuenta todos los establecimientos que se abrieron en cada periodo independientemente de que sigan abiertos en 2017 (Figura 6 y 7). Algunos de estos hoteles han cerrado o fusionado físicamente entre sí, mientras que otros se han reconvertido en apartamentos de alquiler o vivienda. En cambio, el análisis clúster y el estudio del parcelario hotelero ha utilizado únicamente los hoteles que se han mantenido abiertos desde su inauguración hasta 2017 y que figuran en el Registro de Establecimientos Hoteleros de la Junta de Andalucía (59 hoteles). Algunas características de este conjunto son: (i) predominio de hoteles de cuatro estrellas con un total de 25 (42,4\% del total); (ii) la antigüedad media de los establecimientos es de 38,3 años, ya que la mayoría de la planta hotelera se inauguró durante la década de los sesenta y los setenta; (iii) el tamaño medio de los establecimientos es de 339,9 plazas, aunque en el destino se localizan 15 hoteles que superan las 500 plazas, siendo el hotel Sol Príncipe el de mayor dimensión con 1721 plazas. Aunque también se identifican 10 hoteles de reducidas dimensiones, con menos de 50 plazas; (iv) la distancia media de los hoteles con respecto a la playa es de 339,9 metros, ya que sólo 15 establecimientos se encuentran situados en primera línea de playa, la mayoría se localizan en segunda línea y/o junto al núcleo tradicional de Torremolinos. La información proporcionada de los hoteles se ha empleado en el análisis clúster y las agrupaciones correspondientes (Tabla 2 y Figura 11).

La evolución de la oferta hotelera de Torremolinos se puede dividir en tres grandes fases en función del crecimiento de la misma (Figura 6). Estas tres fases están acordes con otros estudios que identifican estas tres etapas en destinos (Almeida, 2012). La fase inicial se corresponde con el turismo de élite que ocupaba los pequeños hoteles familiares próximos a la carretera entre Málaga y Cádiz (Nacional 340). Esta fase comenzaría a principio del siglo XX y llegaría hasta el inicio de la década de los 60. La primera referencia hotelera conocida es la residencia Santa Clara a fines de 
los años 20, iniciativa de un inglés afincado en Torremolinos. Después le seguiría el Parador de Montemar en los años 30, actuación empresarial de la burguesía ilustrada de Málaga. De esta forma a mediados de los años 50 había una significativa oferta de pequeños hoteles coquetos enfocados al turismo extranjero y numerosas fondas y pensiones en el casco antiguo del pueblo. De este período sólo ha sobrevivido uno de los establecimientos hoteleros. El mapa de 1957 identifica 12 hoteles y señala que una buena parte de estos hoteles se situaban en torno a la calle San Miguel que de norte a sur une el centro histórico con la playa y el barrio del Bajondillo, mientras que otros se localizan en las proximidades de la carretera Nacional 340 que cruza Torremolinos de un extremo a otro, separada de la costa (Figura 3).

Figura 6. Evolución de la oferta hotelera de Torremolinos

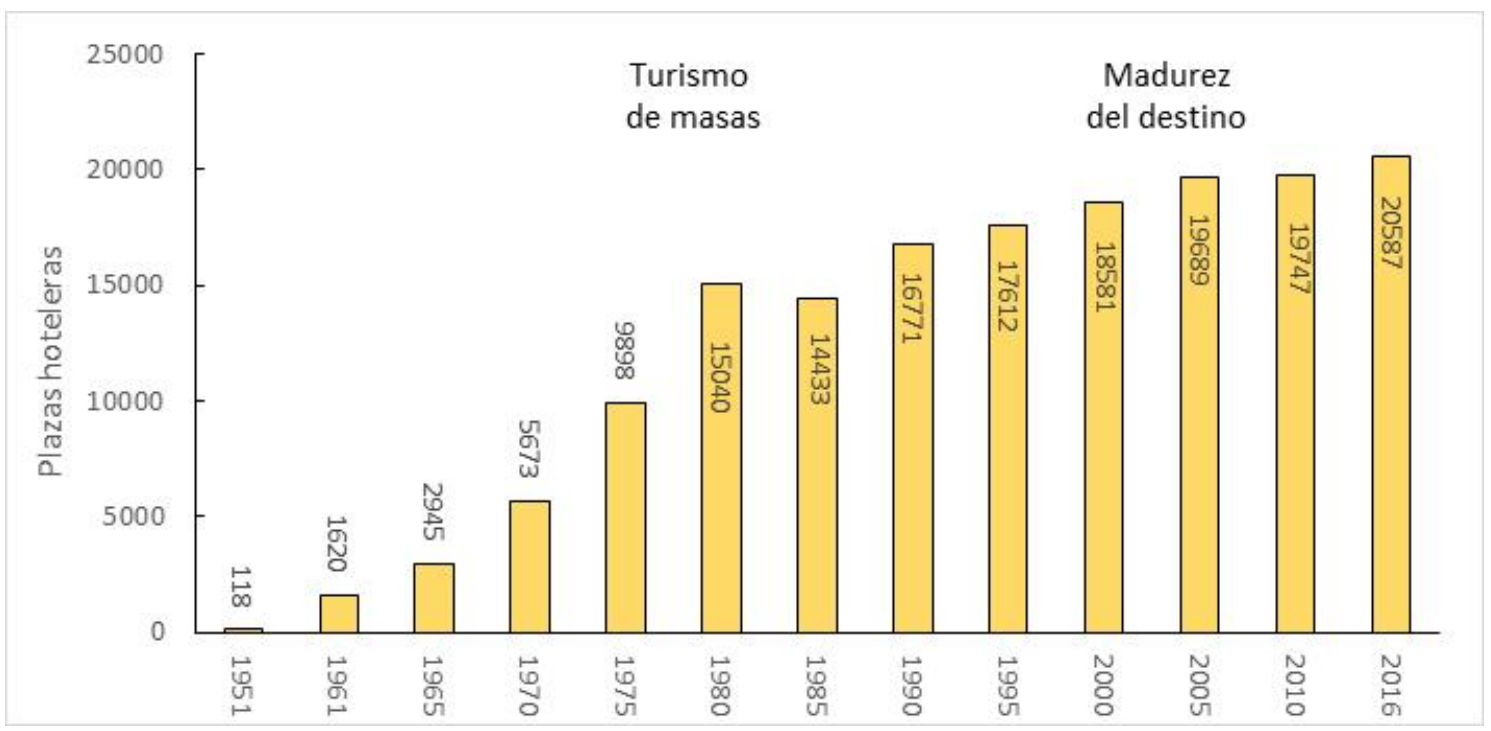

Fuente: elaboración propia a partir

de Guías oficiales de Hoteles de España (1951-1995) e IECA (2000-2016)

La segunda fase comienza a principio de los 60 y termina al comienzo de la década de los 90 del siglo pasado (Figura 4). Esta etapa se caracteriza por la creación de la mayor parte de la planta hotelera de Torremolinos y por el asentamiento del modelo del turismo de masas, aunque al inicio de esta fase el destino aún se presentaba como espacio enfocado al turismo de élite, siendo prueba de ello la existencia de 5 hoteles de 5 estrellas. Esta oferta más cualificada irá disminuyendo progresivamente, de tal forma que en 1990 sólo había un hotel de 5 estrellas y ninguno en 2000. Durante este periodo se produce un fuerte crecimiento de la oferta que se irá enfocando hacia una demanda más popular y amplia. La consolidación de Torremolinos como destino de masas obligará al sector hotelero a desarrollar diversas estrategias de localización.

Entre 1959 y 1969 se abrieron 18 hoteles ubicados principalmente en la zona central del municipio y al oeste en la playa (La Carihuela) (Figura 4 y 8). En estos diez años, que anuncian la irrupción del turismo de masas en Torremolinos, concurren al mismo tiempo, los establecimientos de 
pequeño tamaño, que están situados en la zona central de la ciudad y los grandes hoteles que se disponen junto a la playa como Pez Espada (1959), Meliá Costa del Sol (1963) o Nautilus (1964). El área ocupada por el parcelario de los hoteles era de 71544,32 $\mathrm{m}^{2}$. El tamaño promedio fue $3.74,68 \mathrm{~m}^{2}$, oscilando entre $9500 \mathrm{~m}^{2}$ de parcela de los grandes hoteles de 4 estrellas y 250$300 \mathrm{~m}^{2}$ de parcela de los pequeños hoteles de 2 y 3 estrellas (Figura 9).

Figura 7. Localización y tendencias de los hoteles en Torremolinos (2017).
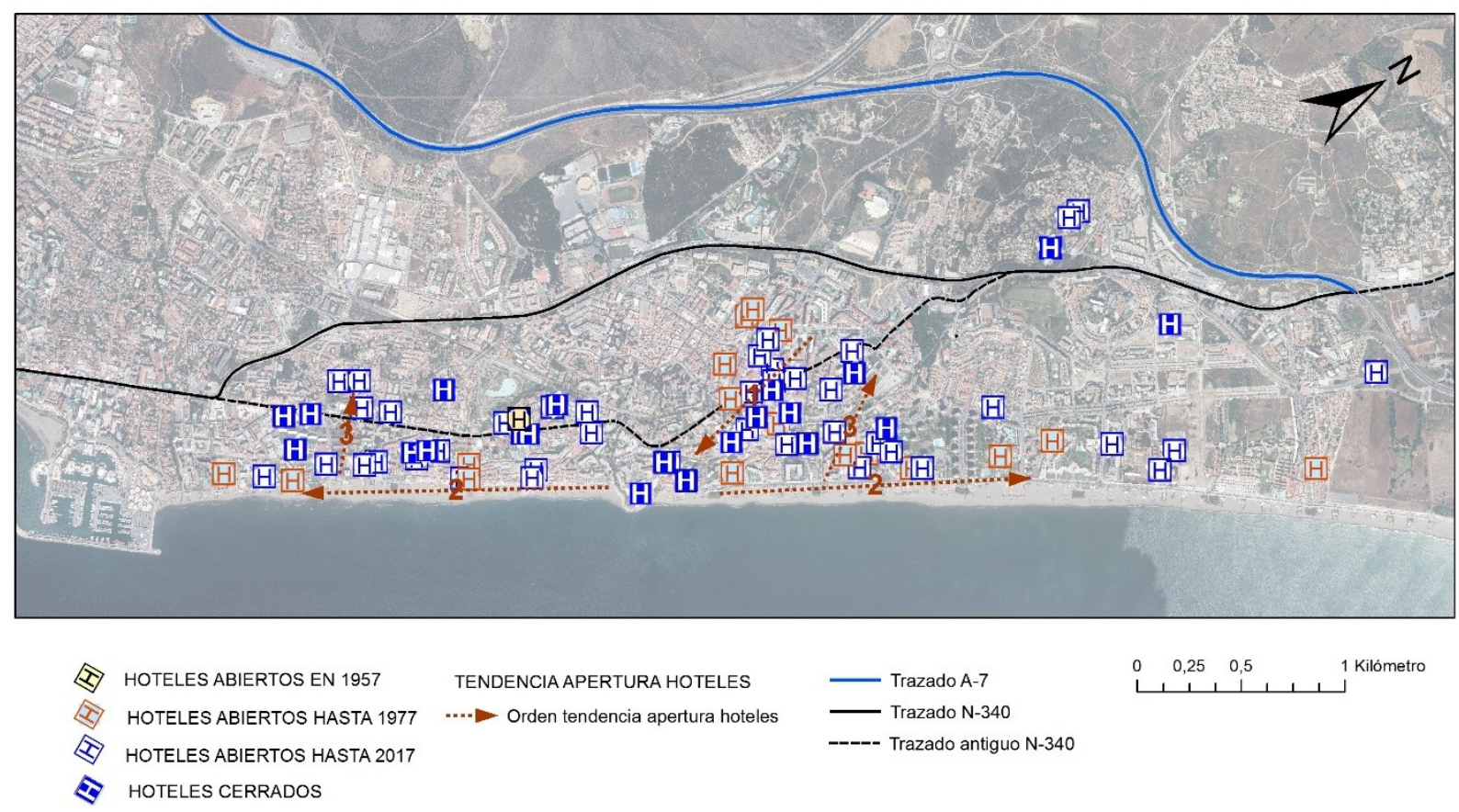

Fuente: elaboración propia

La consolidación del turismo de masas, se acompañó de una intensificación de la implantación hotelera en los años siguientes. Entre 1970 y 1979, abrieron sus puertas 16 hoteles repartidos principalmente en el centro y este de la ciudad (Figura 8). Según la figura 4, en 1977 estaban abiertos 47 hoteles en esa fecha. A pesar del proceso de popularización del destino, éste mantiene ciertos elementos del periodo de élite anterior, de tal forma que se mantienen cuatro de hoteles de cinco estrellas (el mismo número de hoteles de 5 estrellas que en Marbella en la misma fecha). El área total de la oferta hotelera es mayor que en la década anterior (105 001,15 m²) y la parcela promedio también $\left(6562,57 \mathrm{~m}^{2}\right)$. En los 70 los grandes hoteles se localizan en las zonas más cercanas a la playa, colonizando y colmatando el frente costero, mientras que los pequeños hoteles de categoría inferior se encuentran en segunda línea de playa. La presencia de grandes hoteles se relaciona con la expansión de las cadenas hoteleras españolas (Sol-Meliá, Riu, etc.) y otras franquicias internacionales (Blázquez, Cañada \& Murray, 2011; Blázquez, Murray \& Artigues, 2011), mientras que los pequeños hoteles familiares quedan en una posición secundaria y económicamente más débil. El aumento en el tamaño del hotel está estrechamente relacionado con el fuerte crecimiento de la demanda y la opción empresarial por la popularización de su oferta 
(Figura 9). La cercanía de Torremolinos al aeropuerto (menos de 10 kms.) aseguraba la llegada ininterrumpida de turistas.

Figura 8. Localización en 2017 de los hoteles en Torremolinos según año apertura

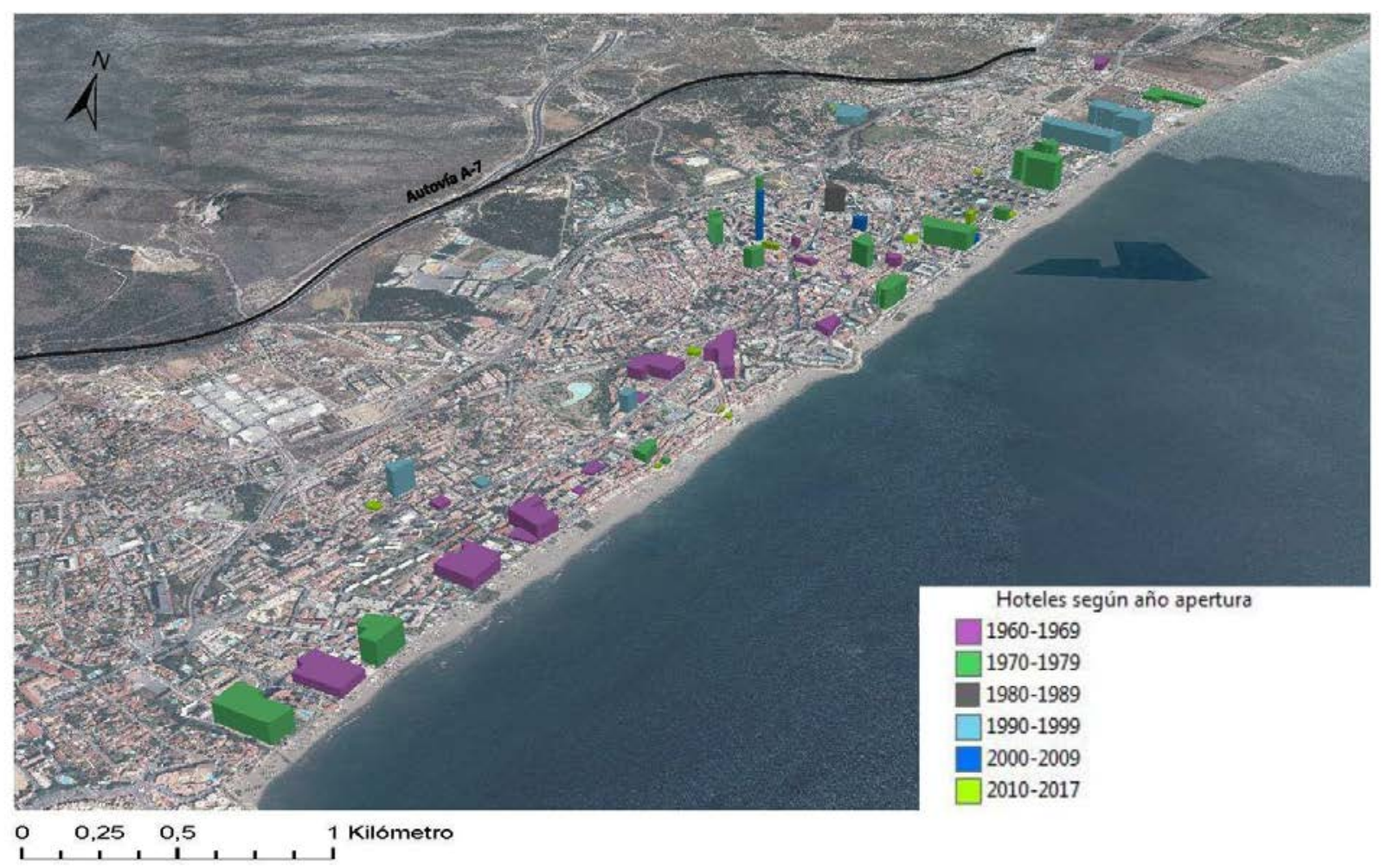

Fuente: elaboración propia

La tercera fase que se inicia en 1990, se caracteriza por la madurez de la oferta hotelera, que se traduce en menores inauguraciones de hoteles, tendencia a un crecimiento débil de la oferta de plazas hoteleras y la reconversión de las existentes (Figura 5, 7 y 10). En 1990 la oferta hotelera fue de 18750 plazas, que se mantiene como el techo de alojamiento durante bastante tiempo. De todos modos, hay que destacar que entre 1990 y 2000 iniciaron su andadura 10 hoteles. Estos alojamientos se encuentran en el este y el norte, que eran las zonas menos saturadas en ese momento desde el punto de vista urbano. Algunos de ellos, se pudieron localizar sobre los últimos suelos costeros sin urbanizar (Los Álamos). La superficie del parcelario total fue de $80422,11 \mathrm{~m}^{2}$ y la parcela media fue de $8042,2 \mathrm{~m}^{2}$, un tamaño más elevado que los casos anteriores. Este hecho confirma la tendencia al aumento del tamaño de la parcela del hotel (Figura 9), acorde con la economía de escala y con la oferta del todo incluido que reduce costes e incrementa beneficios (Simancas \& Cruz, 2010). Para este periodo, la ocupación total de las parcelas de hoteles en la ciudad de Torremolinos suponía 27,8 hectáreas.

En resumen, la mayor parte de la oferta surgió en la década de los sesenta y los setenta, ya que 41 de los actuales establecimientos y el $86,5 \%$ de las plazas se inauguraron en ese período. Entre los 
hoteles abiertos actualmente sólo 18 se pusieron en marcha en el período comprendido entre 1980 y 2017.

Figura 9. Extensión media de la parcela hotelera según año de apertura (Torremolinos)

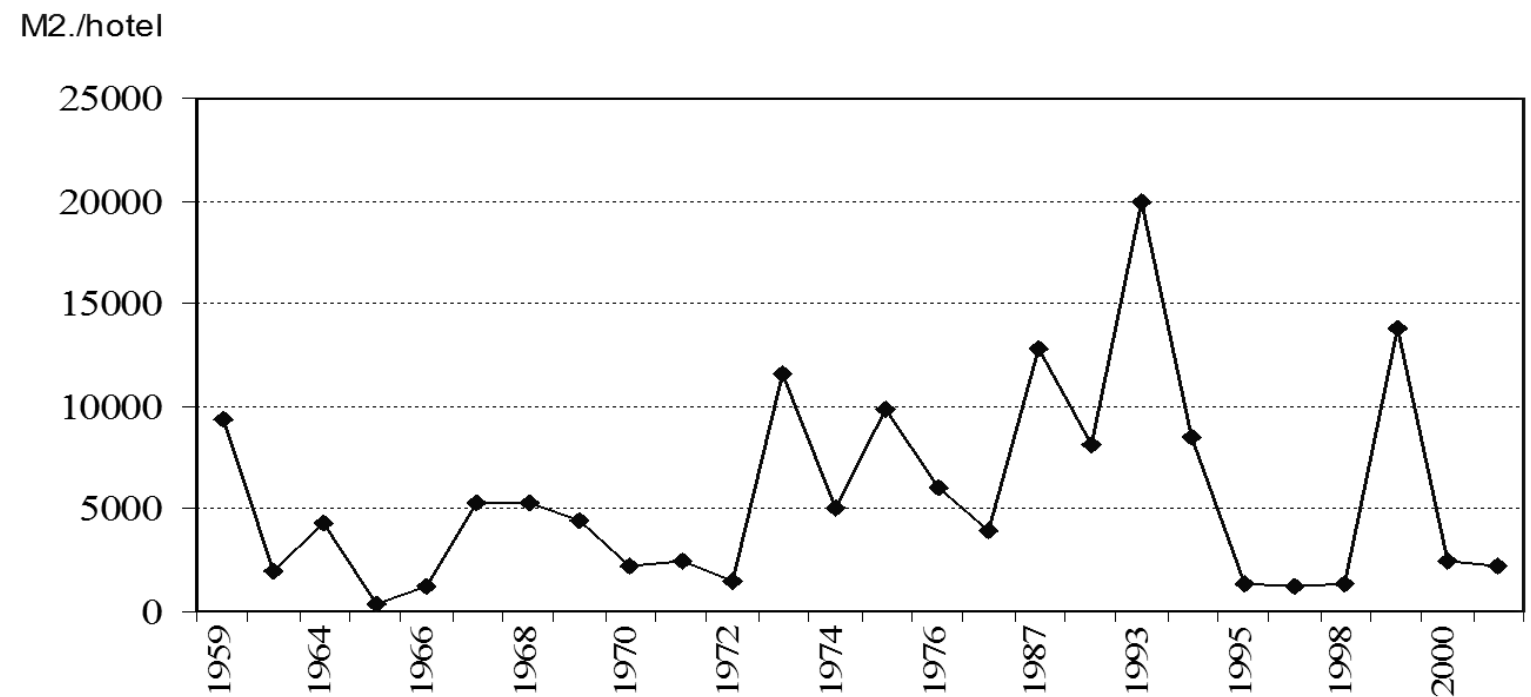

Fuente: elaboración propia

\subsection{Panorama reciente de la hotelería en Torremolinos}

En los últimos años se ha registrado significativos cambios en el sector. A finales de la década de los 90 se produjo una reducción de la oferta que obedeció a cierres por reconversión. La crisis económica de 2008 mantuvo casi congelado el número de plazas y sólo en los últimos años se observa un ligero crecimiento (Figura 6).

Las pernoctaciones se redujeron un 18,5\%, pasando de 5177878 (1999) a 4220252 (2011), aunque en 2016 se habían recuperado (4873 516) y estas cifras se mantienen en 2017 (4 878 563). Así mismo, se ha recobrado la afluencia de viajeros turísticos, pero con un ritmo algo diferente: 936325 (1999), 901981 (2011), 882896 (2016) y 993189 (2017), por lo que se ha producido un fuerte incremento entre 2016 y 2017 (INE, 1999-2017). La rentabilidad general del destino ha experimentado una disminución en estos últimos debido sobre todo a la crisis económica, que inicialmente fue especialmente dura para los destinos maduros y masivos que tenían cierta dependencia del turismo interno. Así pues, se produjo una fuerte reducción de los ingresos medios por habitación (RevPar) entre el año 2000 (52,8 $€$ ) y 2009 (44,5€), habiéndose recuperado en 2016 (62,7€) (Exceltur, 2000-2016; Thiel, 2011). En cualquiera de las fechas citadas, Torremolinos estaba por debajo de la media nacional en RevPar.

Hay que destacar también el proceso de cualificación que se ha producido en el último período (Figura 10). Respecto a las categorías de la oferta hotelera, se observa un progresivo incremento 
de la oferta superior. En 2016 las plazas hoteleras de cuatro estrellas suponían el 77,3\% de las plazas totales, situación que es parte del intenso proceso de reconversión que ha experimentado la planta hotelera en los últimos 20 años. De esta forma, entre 1991 y 2016, las plazas de hoteles de 4 estrellas se han incrementado un 527,5 \% (2328 a 14609 plazas), mientras que las plazas de categorías inferiores (1, 2 y 3 estrellas) se han reducido claramente (de 10735 a 4283 plazas en el mismo periodo) (IECA, 2017). A pesar de esta apuesta por la calidad, en la actualidad no existe en Torremolinos ningún hotel de categoría 5 estrellas. El último establecimiento de esta categoría que quedaba en el municipio era el Hotel Meliá Tres Carabelas, el cual bajó de categoría en el año 1993 y fue demolido en el año 2007 para la construcción de un futuro nuevo hotel de cinco estrellas, cuyas obras están paralizadas.

Figura 10. Evolución de la oferta hotelera en Torremolinos por categorías

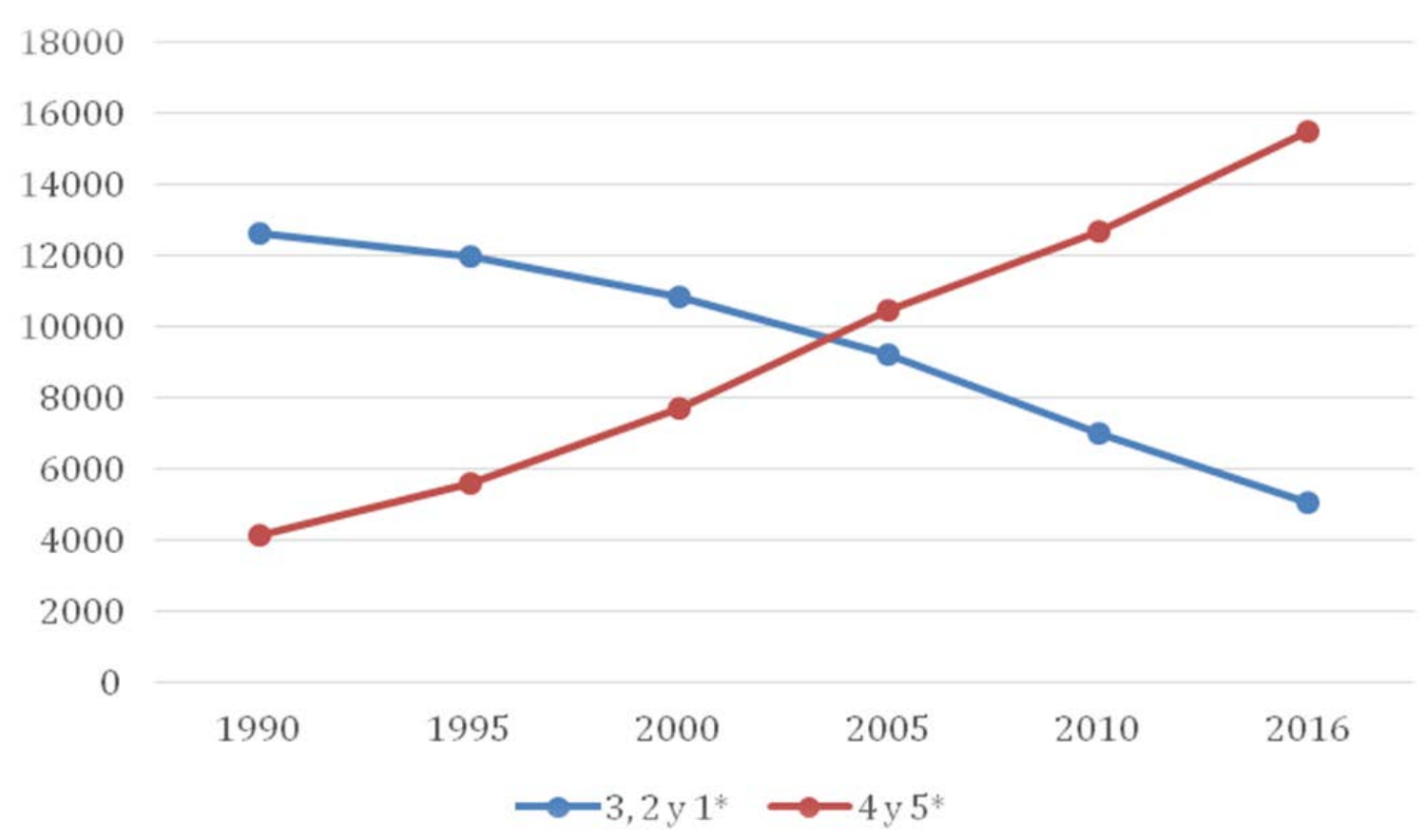

Fuente: IECA (2017)

En los últimos años, se han inaugurado 7 establecimientos hoteleros de baja categoría ya que ninguno es de cuatro estrellas y que cuentan una media de 35 plazas y una parcela media pequeña, con unas dimensiones de unos $739 \mathrm{~m}^{2}$. Algunos de estos establecimientos surgen para atender las tendencias de la nueva demanda, caracterizada en muchos casos por ofrecer alojamientos que van destinados a unos segmentos muy específicos como el kosher o el halal u hoteles tematizados. Estos establecimientos se ubican principalmente en las áreas urbanas consolidadas, tanto en la primera línea de costa como en el interior. 


\subsection{Análisis clúster de la oferta hotelera}

A partir de las variables indicadas en el apartado de la metodología y siguiendo las recomendaciones de Fernández (1991), se realizó un análisis clúster o de aglomerados mediante una agrupación jerárquica utilizando el método de Ward (distancia euclídea al cuadrado), el cual permitió la identificación de 8 grupos de hoteles (Tabla 2 y Figura 11). Los grupos con mayor número de miembros son los conglomerados 1, 3 y 4 cuyas principales características son las siguientes:

(i) Conglomerado 1. Este grupo está formado por el mayor número de hoteles (15), los cuales representan el 25,42\% del total. Como principales características de estos hoteles podemos destacar que casi en su totalidad son de 4 estrellas, situados en primera línea de playa, con un gran tamaño de parcela y una media notable de plazas $(341,3)$ y unos precios elevados. La antigüedad de estos hoteles es significativa (media de 48 años), según los patrones de localización del apartado 4.2 se corresponden con establecimientos que abrieron a principios del período del turismo de masas y en su mayoría se localizan en la zona litoral occidental del municipio debido principalmente a la proximidad de la principal vía de comunicación, respecto a la costa

(ii) Conglomerado 3. Este grupo está formado por 12 establecimientos de 3 estrellas que se localizan en la segunda línea de playa (distancia media de 392 m), con una parcela pequeña, reducida cantidad de plazas y precios más bajos que el anterior. Este conjunto de hoteles tiene una antigüedad notable, muchos fueron de los primeros en abrir al inicio del período del turismo de masas, debido a su cercanía al núcleo tradicional y su localización junto a su trama urbana en el interior.

(iii) Conglomerado 4. Al igual que en agrupamiento anterior está formado por 12 hoteles, que se caracterizan como hoteles de segunda línea ya que su distancia media a la playa es de $425,6 \mathrm{~m}$. En su mayoría se localizan al oeste del municipio cerca del antiguo trazado de la Nacional 340. Este grupo de alojamiento está formado por hoteles de categoría diversa, ya que aparecen hoteles de 1 y 2 estrellas junto a otros de 3 y de 4 . Otros aspectos que identifican este grupo es que se corresponden con establecimientos que han abierto recientemente ya que su antigüedad media es de 14,6 años y que poseen un promedio de plazas reducido (105), este tipo de hoteles se corresponden con los surgidos durante los últimos años de la fase de madurez.

Por último, se han identificado una serie de agrupamientos con un número pequeño de componentes que hemos denominado Miniconglomerados (2, 5, 6, 7 y 8). Estos agrupamientos están formados por hoteles que poseen algunas características particulares que los diferencian de los tres anteriores. 
El grupo 2 que está integrado por dos hoteles que se sitúan en tercera línea a gran distancia de la playa (1409 m), son de apertura reciente y de un promedio muy bajo de plazas (55) y se corresponden a un establecimiento de 2 y 3 estrellas.

El grupo 5 está integrado por 5 establecimientos de baja categoría (1 y 2 estrellas) que se encuentran en primera o segunda línea, se localizan en áreas del núcleo tradicional de Torremolinos ofreciendo un número reducido de plazas $(34,6)$, con el precio más reducido de los grupos de hoteles analizados.

El grupo 6 está integrado por 4 establecimientos de 4 y 3 estrellas que se sitúan en segunda línea y un elevado número de plazas (726) y precio intermedio. Se localiza en la zona tradicional como el grupo 3 pero a diferencia de éste, los hoteles tienen mayores dimensiones.

El grupo 7 está integrado por 7 establecimientos situados en primera línea, en su mayoría son establecimientos de 4 estrellas caracterizados por poseer los precios más elevados del municipio y gran número de plazas. Estos hoteles se localizan en la zona oriental del litoral.

El grupo 8 está integrado por dos establecimientos de cuatro estrellas caracterizados por poseer las mayores parcelas, un elevado número de plazas, situarse en primera y tercera línea y poseer también un precio elevado. Son hoteles que se especializan en el "todo incluido".

Figura 11. Localización de los hoteles según clúster de pertenencia.
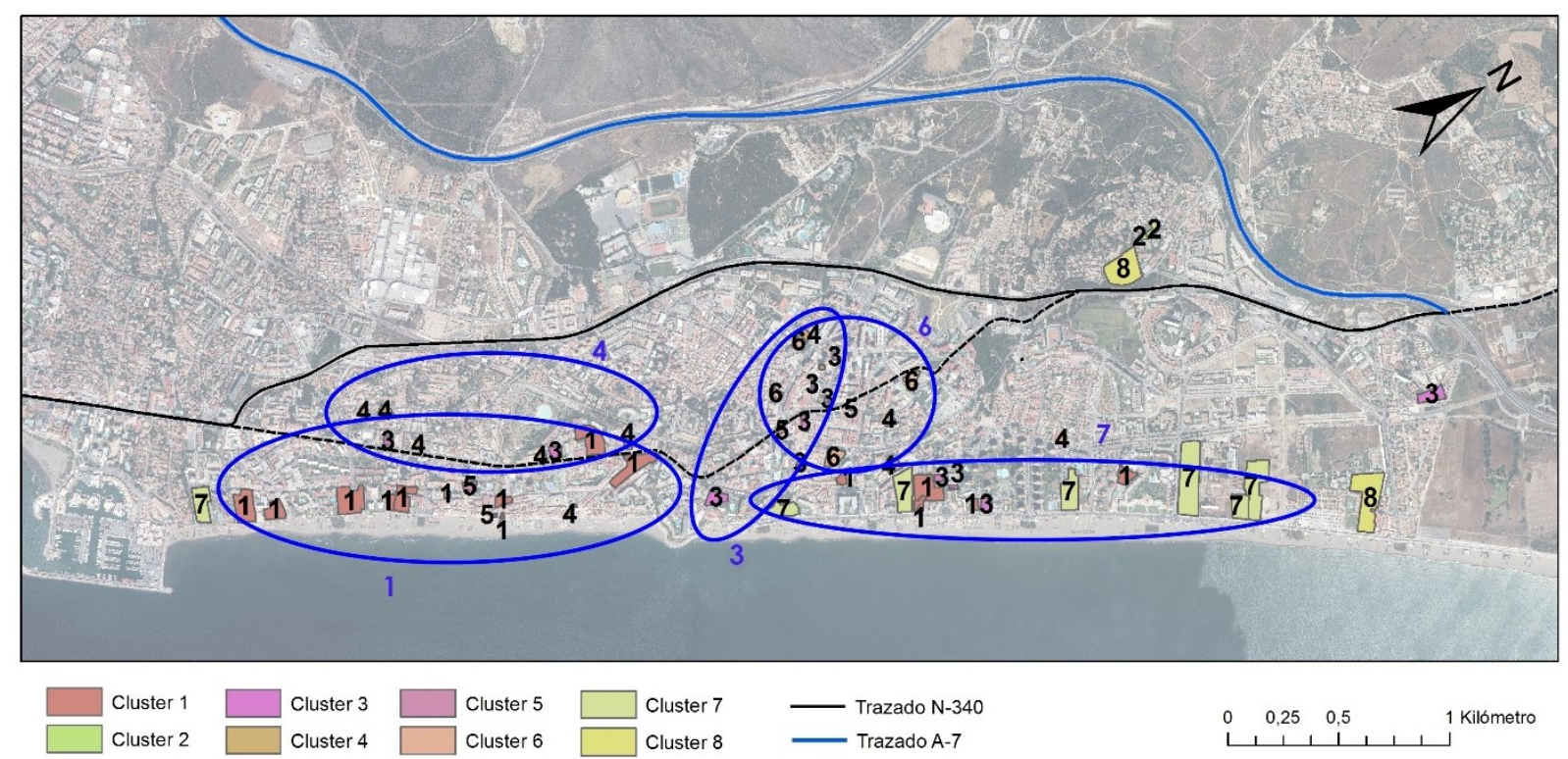

Fuente: elaboración propia 
Tabla 2. Características de los conglomerados

\begin{tabular}{|c|c|c|c|c|c|c|c|}
\hline & $\begin{array}{l}\text { Categoría } \\
\text { (Estrellas) }\end{array}$ & Área $\left(\mathrm{m}^{2}\right)$ & $\begin{array}{c}\text { Plazas } \\
\text { (cantidad) }\end{array}$ & $\begin{array}{l}\text { Distancia } \\
\text { playa }(\mathrm{m})\end{array}$ & $\begin{array}{c}\text { Precio }(€) \\
\text { (habitación } \\
\text { doble) }\end{array}$ & $\underset{\text { (años) }}{\text { Antigüedad }}$ & $\begin{array}{l}\text { Número } \\
\text { de } \\
\text { hoteles }\end{array}$ \\
\hline $\begin{array}{l}\text { Conglomerado } 1 \\
1^{\mathrm{a}} \text { línea de playa }\end{array}$ & $\begin{array}{c}\text { Mayoría } \\
4 *\end{array}$ & 4728,7 & 341,3 & 135,3 & 190,6 & 48,0 & 15 \\
\hline $\begin{array}{l}\text { Miniconglomerado } 2 \\
3^{a} \text { línea de playa }\end{array}$ & $3 *$ y 2 * & 1056,8 & 55,0 & $1.409,6$ & 111,5 & 14,0 & 2 \\
\hline 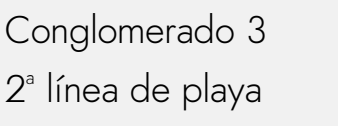 & $\begin{array}{l}\text { Todos } \\
3 *\end{array}$ & 1773,6 & 180,75 & 392,1 & 114,5 & 50,7 & 12 \\
\hline $\begin{array}{l}\text { Conglomerado } 4 \\
2^{a} \text { línea de playa }\end{array}$ & Diversas & 1260,4 & 105,9 & 425,6 & 118,5 & 14,6 & 12 \\
\hline $\begin{array}{l}\text { Miniconglomerado } 5 \\
1^{\mathrm{a}} \text { y } 2^{\mathrm{a}} \text { línea de playa }\end{array}$ & $1^{\star}$ y $2^{*}$ & 935,5 & 34,6 & 209,8 & 90,6 & 48,0 & 5 \\
\hline $\begin{array}{l}\text { Miniconglomerado } 6 \\
2^{a} \text { línea de playa }\end{array}$ & $4^{*}$ y $3^{*}$ & 3556,8 & 726,0 & 599,9 & 157,7 & 41,0 & 4 \\
\hline $\begin{array}{l}\text { Miniconglomerado } 7 \\
1^{\mathrm{a}} \text { línea de playa }\end{array}$ & $\begin{array}{c}\text { Mayoría } \\
4 *\end{array}$ & 10588,3 & $1.046,1$ & 97,1 & 269,0 & 36,7 & 7 \\
\hline $\begin{array}{l}\text { Miniconglomerado } 8 \\
1^{\mathrm{a}} \text { y } 3^{\mathrm{a}} \text { línea de playa }\end{array}$ & $4^{*}$ & 22524,2 & 681,0 & 631,0 & 206,5 & 34,0 & 2 \\
\hline
\end{tabular}

Fuente: elaboración propia

\section{Conclusiones}

Esta investigación aporta un modelo de análisis de localización y comportamiento espacial de la actividad hotelera de un destino. Este modelo se apoya en dos componentes principales: uno transversal relativo a las variables que caracterizan el entorno y las propias del establecimiento; y una componente horizontal, que incorpora la variable cronológica. La combinación de estos dos elementos facilita la compresión de los procesos de localización en cada momento y los cambios que se producen en cada fase. Dentro de los estudios geográficos y turísticos no abundan las reflexiones sobre el comportamiento espacial de los hoteles, a pesar del importante papel que suelen tener en el proceso de creación de los espacios urbanos en los destinos turísticos. Los hoteles juegan una función dinamizadora en los espacios turísticos dentro de los procesos de crecimiento urbano, del mismo modo que la han desempeñado las industrias en los espacios secundarios o los centros administrativos, comerciales o financieros en los espacios terciarios.

Respecto a la distribución espacial de los hoteles, el análisis clúster y evolutivo del destino proporcionan las siguientes pautas de implantación hotelera para Torremolinos: 
a) En primer lugar, se ha identificado que en la primera línea de costa la implantación mayoritaria se corresponde con hoteles que se levantaron en la fase inicial del turismo de masas, fundamentalmente a principios de los años sesenta; poseen una categoría de cuatro estrellas, se han construido sobre parcelas de una dimensión considerable y ofertan un número elevado de plazas (grupo 1). De forma más minoritaria, en la primera línea de costa se ha localizado también un grupo de hoteles que se diferencian de los anteriores por estar construidos a finales de los sesenta o principios de los setenta, poseer un mayor número de plazas, una parcela mayor que los anteriores y unos precios más elevados (grupo 7). Esos establecimientos se corresponden en muchos casos a hoteles cuyo precio es el reflejo de las acciones llevadas a cabo para mejorar la calidad de las instalaciones y/o su orientación hacia el modelo del todo incluido. La mayoría de estos hoteles pertenecen a grandes cadenas hoteleras internacionales. Los hoteles de la primera línea de costa representan la mayoría de la oferta de alojamiento $(60,5 \%$ del total de plazas). La localización de estos hoteles se observa con claridad en la figura 8.

b) En la segunda línea de costa destaca la presencia de hoteles de tres estrellas (grupo 3). El aumento de la distancia a la costa hace que disminuya la categoría de los establecimientos y su precio por habitación. Estos establecimientos tienen una parcela más reducida y un número menor de plazas que los de primera línea (10,6 \% de la oferta); buena parte se localizan dentro del núcleo tradicional de Torremolinos y fueron construidos principalmente en la primera mitad de los años sesenta. Este tipo de hotel se ha especializado en un turismo popular de reducido poder adquisitivo y por otro lado, se mantienen muchos de ellos como hotel de gestión familiar o independiente.

c) También en la segunda línea de costa se localizan hoteles que se han abierto en fecha más reciente (grupo 4). Una vez ocupada la primera línea y casi en su totalidad la segunda, esta zona es la única donde se pueden ubicar nuevos hoteles. Estos establecimientos no se ajustan a una categoría concreta ya que se corresponden a hoteles de 1, 2, 3 y 4 estrellas y también la oferta de plazas es variada $(6,2 \%$ de plazas). Estos hoteles tienden a la segmentación de la demanda, en muchos casos se presentan como hoteles temáticos y la oferta de servicios es amplia. Dentro de esta segunda línea, se identifica la presencia del grupo 6 que está formado por hoteles de 3 y 4 estrellas, precio intermedio, grandes dimensiones y un elevado número de plazas (14,2\% plazas).

d) Por último, hay que añadir que no siempre la ubicación de los hoteles analizados responde a pautas generales de localización u otras variables utilizadas en este estudio. La localización de algunos hoteles se explica por criterios de oportunidad de compra o factores externos al destino. Estos hoteles se corresponderían con los minicluster (2, 5, 7 y 8). 
El análisis de conglomerados identifica la existencia de clústeres espaciales que responden a las pautas de localización desarrolladas por la industria hotelera de Torremolinos, por tanto se puede admitir la hipótesis inicial del estudio.

Esta distribución de grupos de hoteles es consistente con el modelo incluido en Barrado et al. (2001). Hoteles de grandes dimensiones en la primera línea de costa (grupo 1), con precios elevados debido a la proximidad a la playa (la atracción principal) y por ofertar plazas en categorías superiores. En la segunda línea de costa, los hoteles tienen una categoría inferior, suelen tener menores dimensiones (grupo 3) y precios más bajos debido a su mayor distancia a la playa, siendo el precio la principal estrategia para atraer a los clientes. $Y$ en tercer lugar, otros grupos de hoteles de segunda y tercera línea de costa (grupo 8 y 6), presentan precios más elevados que los anteriores, gracias a que han podido desarrollar una amplia oferta de servicios para competir con los hoteles de primera línea. Debemos destacar que la distancia a la playa juega un papel principal en el precio de los hoteles, de tal forma que como promedio por cada $10 \mathrm{~m}$ que nos alejamos hacia el interior el precio se reduce en $9,01 €$.

Las pautas de localización de los hoteles han ido variando en el tiempo conforme a cambios en la demanda y otras variables externas relacionadas con la accesibilidad (carreteras, aeropuerto) y con factores de gestión de estos establecimientos. Los hoteles se distribuyen en la actualidad por todo el municipio, aunque predominan en la primera línea de playa (Figura 8). Siguiendo la evolución histórica del destino, los hoteles se han trasladado desde el núcleo tradicional del municipio a la primera línea de la playa y desde allí a la segunda y tercera línea de costa (Figura 7).

Durante el periodo analizado, se observa el cese de la actividad hotelera de algunos establecimientos. Entre las causas se puede señalar reducción de la rentabilidad a la lo largo del tiempo, la obsolescencia de las instalaciones y la falta de interés por su modernización o viabilidad. Los gestores prefirieron la conversión de los hoteles en establecimientos residenciales. A ello hay que añadir cambios en la gestión, especialmente en periodo de crisis que dio lugar al cierre debido a problemas económicos. Los hoteles que cerraron se localizan principalmente en segunda línea de costa, estos alojamientos suman a las causas anteriormente citadas, la lejanía a la playa y la ausencia de algunos servicios (aparcamientos, comercio, etc.).

Durante la fase de madurez del destino, la mayoría de hoteles que disponían de una parcela amplia o que podían incrementarla, así lo han hecho. La hotelería ha desarrollado estrategias de gestión tendentes a reducir los costes de explotación, ofreciendo una mayor oferta de camas e incluyendo el paquete turístico del "todo incluido". Este enfoque comercial de los hoteles busca adaptarse a las exigencias de un mercado maduro y masivo. El cercano aeropuerto de Málaga y la llegada de los vuelos de bajo coste han proporcionado una amplia materia prima (el turista de masas), que dispone de un poder adquisitivo limitado por lo que los hoteles han creado 
procedimientos para sacarle la máxima rentabilidad a este tipo de turista. Por otro lado, otros hoteles de Torremolinos han combinado la actividad de ocio tradicional con el turismo de congresos, salud, junto con el turismo invernal de personas mayores y la hotelería temática. Otras apuestas como el hotel-condominio se han paralizado debido a la reciente crisis.

Por último, es preciso señalar que a pesar de la vitalidad mostrada por la hotelería de Torremolinos a lo largo del tiempo, se enfrenta en los últimos años a diversos desafíos. En primer lugar, como en cualquier destino maduro en el Mediterráneo español, hay una oferta turística no reglada notable que junto con la oferta de las plataformas "colaborativas" de internet, suponen un reto singular. En segundo lugar, se constata el crecimiento de la oferta hotelera aunque el número de pernoctaciones se mantiene estable lo que puede afectar negativamente a la rentabilidad del sector. En resumen, las estrategias de localización y gestión son las que han permitido mantenerse en activo cada hotel en función de la oferta de sus servicios y la demanda disponible. Esta situación es acorde con diversos estudios sobre hotelería en otros destinos (Bull, 1998; Chou, Hsu \& Chen, 2008; Pereira, Claver \& Molina, 2011; Yang, Lou \& Law, 2014; Lado-Sestayo et al., 2016).

Agradecimientos: El presente artículo es resultado de la investigación realizada dentro del proyecto de investigación "Crisis y reestructuración de los espacios turísticos del litoral español" (CSO2015-64468-P). Financiado por el Ministerio de Economía, Industria y Competitividad (Subdivisión de programas temáticos científico-técnico) y los Fondos FEDER (Unión Europea).

Declaración responsable: Las/os autoras/es declaran que no existe ningún conflicto de interés en relación a la publicación de este artículo. Fernando Almeida García se ha encargado del diseño de la investigación, análisis estadístico y la redacción principal del texto. Rafael Cortés Macías se ha encargado del análisis estadístico, elaboración de las conclusiones y revisión del texto. Erica Schenkel se ha encargado de la elaboración del marco teórico y Antonio Gallegos Reina se ha encargado de la elaboración de la cartografía y la revisión del texto. 


\section{Bibliografía}

Almeida, F. (2012). La política turística de España y Portugal. Cuadernos de Turismo, 30, 9-34.

Alonso, A. U., \& Calderón, M. I. G. (2006). Localización de hoteles urbanos. Madrid, 19361998. Annals of Tourism Research en español, 8(1), 71-96.

Arbel, A., \& Pizam, A. (1977). Some determinants of urban hotel location: The tourists' inclinations. Journal of Travel Research, 15(3), 18-22.

Averbakh, I., \& Berman, O. (1995). Probabilistic sales-delivery man and sales-delivery facility location problems on a tree. Transportation Science, 29(2), 184-197.

Barrado, D., \& Calabuig, J. (2001). Geografía Mundial del Turismo. Madrid: Síntesis.

Baum, J., \& Haveman, H. (1997). Love the neighbour? Differentiation and agglomerations in the Manhattan hotel industry, 1898-1990. Administrative Science Quarterly, 42(2), 304-338.

Baum, J., \& Sign, J. (1994). Organizational niches and the dynamics of organizational mortality. American Journal of Sociology, 100, 346-380.

Blázquez, M., Cañada, E., \& Murray, I. (2011). Búnker playa-sol. Conflictos derivados de la construcción de enclaves de capital transnacional turístico español en El Caribe y Centroamérica. Scripta Nova, 15(368), 741-798. Retrieved from http://www.ub.edu/geocrit/sn/sn-368.htm

Blázquez, M., Murray, I., \& Artigues, A. A. (2011). La balearización global. El capital turístico en la minoración e instrumentación del Estado. Investigaciones Turísticas, 2, 1-28.

Booking (2017). Alojamiento. Hoteles en Torremolinos. Retrieved from www.booking.com

Bull, A. O. (1998). The effects of location and other attributes on the price of products which are place-sensitive in demand (Doctoral dissertation, Griffith University, Australia). Retrieved from

https://researchrepository.griffith.edu.au/bitstream/handle/10072/367767/02Whole.pdf? sequence=1

Cheng, E. W., \& Li, H. (2004). Exploring quantitative methods for project location selection. Building and Environment, 39(12), 1467-1476.

Chou, T. Y., Hsu, C. L., \& Chen, M. C. (2008). A fuzzy multi-criteria decision model for international tourist hotels location selection. International journal of hospitality management, 27(2), 293-301.

Egan, D. J., \& Nield, K. (2000). Towards a theory of intraurban hotel location. Urban Studies, 37(3), 611-621.

EXCELTUR (2000-2016). Barómetro de la rentabilidad de los destinos turísticos españoles 2000-2016. Retrieved from https://www.exceltur.org/barometro-de-la-rentabilidad-y-empleo/ 
Fernández, O. (1991). El análisis de clúster: aplicación, interpretación y validación. Papers: Revista de Sociología, 37, 65-76.

García, E., \& Ocaña, C. (1982). La organización espacial de la costa mediterránea andaluza. Baética, 5, 15-57. Retrieved from https://riuma.uma.es/xmlui/handle/10630/8922

Gormsen, E. (1981). The spatio-temporal development of international tourism, attempt at a centreperiphery model. In Actes du Colloque d'Aix-en-Provence (pp. 150-170). Université de Droit, d’Economíe et de Sciences, September, 6-11. CHET.

Greenhut, M., Norman, G., \& Hung, C. (1987). The economics of imperfect competition: a spatial approach. New York: Cambridge University Press.

Hanna, M., \& Freeman, J. (1989). Organizational ecology. Cambridge: Harvard University Press.

Instituto de Estadística y Cartografía de Andalucía (IECA) (2017). Sistema de información multiterritorial de Andalucía (SIMA). Retrieved from

http://www.juntadeandalucia.es/institutodeestadisticaycartografia/sima/index2.htm

Instituto de Estadística y Cartografía De Andalucía (IECA) (2017, February). Coyuntura Turística Hotelera (EOH/IPH/IRSH). Retrieved from

http://www.ine.es/daco/daco42/prechote/cth0116.pdf

Instituto Nacional de Estadística (INE) (1999-2017). Encuesta de ocupación hotelera 1999-2016.

Retrieved from

https://www.ine.es/dyngs/INEbase/es/operacion.htm?c=Estadistica_C\&cid=1254736177015\& $\underline{\text { menu }=\text { resultados\&id } p=1254735576863}$

Instituto Nacional de Estadística (INE) (2013). Censo de Población y viviendas 2011. Retrieved from http://www.ine.es/censos2011_datos/cen11_datos res edi.htm

Johnson, S. (2006). The ontological Foundation of the TALC. In R. W. Butler (Ed.), The Tourism Area Life Cycle, Volumen 1 (pp. 7-28). Channel View Publications.

Knafou, R. (2006). El turismo, factor de cambio territorial: evolución de los lugares, actores y prácticas a lo largo del tiempo. Presented at the IX coloquio de Geografía del Turismo, Ocio y la Recreación. Zaragoza: Prensas Universitarias de Zaragoza.

Lado-Sestayo, R., Otero-González, L., Vivel-Búa, M., \& Martorell-Cunill, O. (2016). Impact of location on profitability in the Spanish hotel sector. Tourism Management, 52, 405-415.

Ministerial Council (2012). Corine land Cover (CLC). Agencia Europea de Medio Ambiente.Land Core Monitoring System GMES (Global Monitoring for Environment and Security). Retrieved from http://www.esa.int/About_Us/Ministerial_Council_2012/Global_Monitoring_for_Environmen t_and_Security_GMES 
Ministerio de Hacienda y Función Pública (2017). Portal General de la Dirección General del Catastro. Madrid: Dirección General del Catastro. Retrieved from http://www.catastro.meh.es

Murray, I., Yrigoy, I., \& Blázquez, M. (2017). The role of crises in the production, destruction and restructuring of tourist spaces. The case of the Balearic Islands. Investigaciones Turísticas, 13, 1-29. Papatheodorou, A. (2002). Exploring competitiveness in Mediterranean resorts. Tourism Economics, $8,133-150$.

Pereira Moliner, J., Claver Cortés, E., \& Molina Azorín, J. F. (2011). Efectos empresa, grupo estratégico y localización en el sector hotelero español. Cuadernos de Economía y Dirección de la Empresa, 14(2), 123-138.

Pollard, J., \& Domíguez, R. (1993). Tourism and Torremolinos: recession or reaction to environment? Tourism Management, 14(4), 247-258.

Pons, A., Rullan, O., \& Murray, I. (2014). Tourism capitalism and island urbanization: tourist accommodation diffusion in the Balearics, 1936-2010. Island Studies Journal, 9(2), 239-258.

Porter, M. E. (2000). Location, competition, and economic development: Local clusters in a global economy. Economic development quarterly, 14(1), 15-34.

Priestley, G., \& Mundet, L. (1998). The post-stagnation phase of the resort life-cicle. Annals of Tourism Research, 25(1), 85-111.

Rigall-I-Torrent, R., Fluvià, M., Ballester, R., Saló, A., Ariza, E., \& Espinet, J. M. (2011). The effects of beach characteristics and location with respect to hotel prices. Tourism Management, 32(5), $1150-1158$.

Shoval, N. (2006). The geography of hotels in cities: an empirical validation of a forgotten model. Tourism Geographies, 8(1), 56-75.

Simancas Cruz, M., \& García Cruz, J. (2010). El impacto territorial de las estrategias de mejora de la calidad de los destinos maduros: la aplicación de estándares edificatorios a los alojamientos turísticos. In R. Hernández \& A. Santana (Coords.), Destinos turísticos maduros ante el cambio: reflexiones desde Canarias (pp. 161-182). Universidad de la Laguna.

Thiel, D. (2011). Los impactos turísticos en la Costa del Sol: Valoración del desarrollo turístico de Torremolinos a través de un sistema de indicadores de sostenibilidad (Master's Thesis, Universidad de Málaga).

Tripadvisor (2017). Hoteles. Hoteles en Torremolinos. Retrieved from https://www.tripadvisor.es

Turespaña (1995-2017). Guía de hoteles, campings y apartamentos. Madrid: Ministerio de Industria, Turismo y Comercio. 
Urtasun, A., \& Gutiérrez, I. (2006). Hotel location in tourism cities: Madrid 1936-1998. Annals of Tourism Research 33(2), 382-402.

Yang, J., \& An, H. (1997). AHP decision model for facility location selection. Facilities, 15(9/10), $241-254$

Yang, Y., Luo, H., \& Law, R. (2014). Theoretical, empirical, and operational models in hotel location research. International Journal of Hospitality Management, 36, 209-220.

Yang, Y., Wong, K. K., \& Wang, T. (2012). How do hotels choose their location? Evidence from hotels in Beijing. International Journal of Hospitality Management, 37(3), 675-685. 